\title{
Guillain-Barré syndrome after adoptive cell therapy with tumor-infiltrating lymphocytes
}

\author{
Angela Orcurto, ${ }^{1}$ Andreas Hottinger, ${ }^{2,3}$ Benita Wolf, ${ }^{2}$ Blanca Navarro Rodrigo, ${ }^{1,4}$ \\ Maria Ochoa de Olza, ${ }^{1,4}$ Aymeric Auger, ${ }^{4,5}$ Thierry Kuntzer, ${ }^{3}$ Denis Comte (1) ,6 \\ Virginie Zimmer, ${ }^{5}$ Philippe Gannon, ${ }^{5}$ Lana Kandalaft, ${ }^{4,5}$ Olivier Michielin, ${ }^{2}$ \\ Stefan Zimmermann, ${ }^{1}$ Alexandre Harari, ${ }^{4,5}$ Lionel Trueb, ${ }^{1}$ George Coukos ${ }^{1,4}$
}

To cite: Orcurto $A$, Hottinger $A$, Wolf $\mathrm{B}$, et al. Guillain-Barré syndrome after adoptive cell therapy with tumor-infiltrating lymphocytes. Journal for ImmunoTherapy of Cancer 2020;8:e001155. doi:10.1136/ jitc-2020-001155

Accepted 24 July 2020

\section{Check for updates}

(c) Author(s) (or their employer(s)) 2020. Re-use permitted under CC BY-NC. No commercial re-use. See rights and permissions. Published by BMJ.

${ }^{1}$ Immuno-oncology Service, Department of Oncology, CHUV, Lausanne, Vaud, Switzerland

${ }^{2}$ Oncology Service, Department of Oncology, CHUV, Lausanne, Vaud, Switzerland

${ }^{3}$ Service of Neurology,

Department of Clinical

Neurosciences, CHUV, Lausanne,

Vaud, Switzerland

${ }^{4}$ Ludwig Institute for Cancer Research, Lausanne Branch, University of Lausanne, Epalinges, Vaud, Switzerland

${ }^{5}$ Center of Experimental

Therapeutics, Department of Oncology, CHUV, Lausanne,

Vaud, Switzerland

${ }^{6}$ Service of Immunology and Allergy, Department of Medicine, CHUV, Lausanne, Vaud,

Switzerland

Correspondence to

Dr Angela Orcurto;

angela.orcurto@chuv.ch

\section{ABSTRACT}

Background Adoptive cell therapy (ACT) using tumorinfiltrating lymphocytes (TILs) is a promising experimental immunotherapy that has shown high objective responses in patients with melanoma. Current protocols use a lymphodepletive chemotherapy before infusion of ex vivo expanded TILs, followed by high-dose interleukin-2 (IL-2). Treatment-related toxicities are mainly attributable to the chemotherapy regimen and to the high-dose IL-2 and are generally reversible. Neurological side effects have rarely been described. Nevertheless, due to improvements in cell production techniques and due to combinations with other immunomodulating molecules, side effects not previously described may be encountered.

Case presentation We report the case of a 53-year-old heavily pretreated patient with melanoma who developed Guillain-Barré syndrome (GBS) 19 days after ACT using autologous TILs, given in the context of a phase I trial. He presented with dorsal back pain, unsteady gait and numbness in hands and feet. Lumbar puncture showed albuminocytological dissociation, and nerve conduction studies revealed prolonged distal motor latencies in median, ulnar, tibial and peroneal nerves, compatible with a GBS. The patient was treated with intravenous immunoglobulins and intensive neurological rehabilitation, with progressive and full recovery at 21 months post-TILACT. Concomitant to the onset of GBS, a cytomegalovirus reactivation on immunosuppression was detected and considered as the most plausible cause of this neurological side effect.

Conclusion We describe for the first time a case of GBS occurring shortly after TIL-ACT for melanoma, even though we could not identify with certainty the triggering agent. The report of such rare cases is of extreme importance to build on the knowledge of immune cellular therapies and their specific spectrum of toxicities.

\section{BACKGROUND}

Adoptive cell therapy (ACT) using tumorinfiltrating lymphocytes (TIL) is a powerful personalized immunotherapy which can mediate impressive and durable responses in patients with heavily pretreated metastatic melanoma. ${ }^{1}$ Most patients who achieve complete tumor regression after TIL-ACT (up to $20 \%$ ) do not experience later relapses, suggesting that TIL therapy can be curative. TIL-ACT consists of autologous T cells being isolated from the patient's tumor, expanded in vitro and then reinfused to the lymphodepleted patient. T-cell engraftment and expansion require host preparation with a standard lymphodepletion chemotherapy regimen consisting of high-dose cyclophosphamide and fludarabine. After T-cell infusion, patients receive high-dose recombinant interleukin-2 (IL-2) in order to support T-cell expansion and engraftment in vivo. To date, more than 400 patients have been treated with TIL-ACT therapy worldwide. ${ }^{2}$

Overall, TIL-ACT therapy is well tolerated, but management by specialized teams in experienced centers is pivotal to ensure clinical safety and to optimize the benefit of this complex treatment. The most prevalent side effects are linked to the transient myelosuppression, which may result in pancytopenia and febrile neutropenia, and to IL-2 administration, potentially leading to cytokine release syndrome (CRS) with fever, chills, capillary leak syndrome and, rarely, organ failure. ${ }^{3}$ Autoimmune-triggered destruction of melanocytes by the transferred cells occurs infrequently and may result in vitiligo and uveitis. ${ }^{4}$ Neurological adverse events have been rarely reported and consist mostly of mental status changes related to the effects of IL-2 and the following CRS. Here we describe the case of a patient who developed Guillain-Barré syndrome (GBS) shortly after TIL-ACT for a metastatic melanoma.

\section{CLINICAL CASE PRESENTATION}

A 53-year-old Caucasian male patient with a metastatic cutaneous melanoma bearing a BRAF V600E mutation was enrolled in a phase 
Table 1 Laboratory work-up

\begin{tabular}{|c|c|}
\hline General laboratory testing (normal values) & Results \\
\hline CRP (<10 mg/L) & 15 \\
\hline Vitamin $\mathrm{B}_{12}(145-569 \mathrm{pmol} / \mathrm{L})$ & 1316 \\
\hline TSH (0.27-4.2 mUl/L) & 1,82 \\
\hline Serum albumin (35-52 g/L) & 34.8 \\
\hline \multicolumn{2}{|l|}{ CSF testing (normal values) } \\
\hline Total protein (150-450 mg/L) & 2551 \\
\hline Albumin (80-300 mg/L) & 1443 \\
\hline Glucose $(2.4-4.4 \mathrm{mmol} / \mathrm{L})$ & 4 \\
\hline $\mathrm{LDH}(<40 \mathrm{U} / \mathrm{L})$ & 24 \\
\hline Albumin quotient (CSF/blood, $\left.<8 \times 10^{3}\right)$ & 41.5 \\
\hline Protein electrophoresis & $\begin{array}{l}\text { Intrathecal oligoclonal } \\
\text { lgG pattern }\end{array}$ \\
\hline $\begin{array}{l}\text { Bacterial PCR (Neisseria meningitidis, Listeria } \\
\text { monocytogenes, Streptococcus pneumoniae, } \\
\text { Haemophilus influenza) }\end{array}$ & Negative \\
\hline Viral PCR (HSV-1, HSV-2, VZV, CMV, EBV) & Negative \\
\hline Tumorous cytology & Negative \\
\hline \multicolumn{2}{|l|}{ CMV PCR values (copies/mL) } \\
\hline Day 30 post-TIL-ACT & 2600 \\
\hline Day 36 post-TIL-ACT & 9320 \\
\hline Day 41 post TIL-ACT & 2950 \\
\hline Day 48 post-TIL-ACT & 556 \\
\hline \multicolumn{2}{|l|}{ Serologies } \\
\hline CMV, EBV, HSV and VZV & $\begin{array}{l}\text { IgM negative } \\
\text { IgG positive }\end{array}$ \\
\hline HIV, viral hepatitis (B, C and $E)$ & Negative \\
\hline \multicolumn{2}{|l|}{ Autoimmune laboratory analysis } \\
\hline $\begin{array}{l}\text { Rheumatoid factor. } \\
\text { Antineutrophil cytoplasmic antibodies (ANCAs, } \\
\text { such as PR3 and MPO). } \\
\text { Antinuclear antibodies (including SSA, SSB, RNP, } \\
\text { Sm, Scl70, and Jo1). }\end{array}$ & Negative \\
\hline $\begin{array}{l}\text { IgM antibodies against myelin-associated } \\
\text { glycoprotein }\end{array}$ & Negative \\
\hline $\begin{array}{l}\text { Antibodies against gangliosides } \\
\text { Gq1b. } \\
\text { Leucin-rich glioma inactivated } 1 . \\
\text { Contacting associated protein } 2 . \\
\text { N-methyl-D-aspartate receptor. } \\
\text { Aquaporin } 4 \text {. }\end{array}$ & Negative \\
\hline
\end{tabular}

Antibodies against myelin oligodendrocyt glycoprotein

Antibodies against the node of Ranvier

- Antineurofascin 155 and 186.

- Anticontactin

- Anti-Caspr1.

$\begin{array}{ll}\text { Antibody against the antifibroblast growth factor } & \text { Negative } \\ \text { receptor } 3 & \\ \text { Paraneoplastic panel } & \text { Negative } \\ \text { Antineuronal YO. } & \\ \text { Antineuronal HU. } & \end{array}$

ACT, adoptive cell therapy; ANCA, anti-neutrophil cytoplasmic antibodies; CMV, cytomegalovirus; CRP, C reactive protein; CSF, cerebrospinal fluid; EBV, Epstein-Barr virus; $\mathrm{HSV}$, herpes simplex viru; $\mathrm{HU}$, antineuronal nuclear antibody; $\mathrm{LDH}$, lactate dehydrogenase; TIL, tumor-infiltrating lymphocyte; TSH, thyroid stimulating hormone VZV, varicella zoster virus; YO, purkinje cell cytoplasmic antibody.

I clinical trial based on TIL-ACT approximately 3 years following initial diagnosis. The main objective of the trial was to assess feasibility and safety of TIL-ACT therapy in metastatic patients with melanomas. His disease was refractory to several lines of treatment, including v-RAF murine sarcoma viral oncogene homolog B (BRAF) and mitogen-activated protein kinase kinase (MEK) inhibitors, anti-programmed-death 1 (PD1) and anti-cytotoxic T-lymphocyte-associated antigen-4 (CTLA-4) therapy. Relevant comorbidities included a postherpetic right dorsal neuralgia and lymphedema of the lower left limb of approximately 3 years due to prior left inguinal mass ablation, lymphadenectomy and adjuvant radiation for melanoma.

TILs were expanded from a subcutaneous clavicular metastasis in the presence of high-dose IL-2, following a conventional pre-rapid expansion protocol (pre-REP) and REP, using autologous feeder peripheral blood mononuclear cells (PBMCs). The patient was treated with standard lymphodepleting non-myeloablative chemotherapy regimen of cyclophosphamide $(60 \mathrm{mg} / \mathrm{kg} /$ day for 2 days) and fludarabine $\left(25 \mathrm{mg} / \mathrm{m}^{2} /\right.$ day for 5 days), followed by the infusion of $55 \times 10^{9}$ TILs. The infused cell product contained mainly effector-memory $\mathrm{T}$ cells, with a CD4+/CD8+ T-cell ratio of 1:1. Due to transient acute renal insufficiency and oliguria, only two doses of highdose IL-2 (720,000 UI/kg/dose) were given. The patient experienced a rapid recovery from all expected toxicities related to myelosuppression and IL-2 and was discharged 2 weeks after the TIL infusion.

Five days after discharge (day 19 post-TIL-ACT), he was readmitted for acute onset dorsal back pain at the thoracic (T6-T8) and lumbar (L1-L4) region, and numbness and tingling sensation in his hands and feet. He also described an unsteady gait. On examination, he had a broad-based gait with a Romberg sign, absence of deep reflexes in the lower limbs, and loss of vibration sense in the knees, ankles and big toes. Extensors and flexors of the feet and toes were weak (MRC4).

The initial work-up, including brain and spine MRIs, was normal. Nerve conduction studies revealed prolonged distal motor latencies, desynchronization of the compound muscle action potentials for the median, ulnar, peroneal and tibial nerves and absence of F-waves. Sensory nerve action potentials were reduced in the lower limbs. The cerebrospinal fluid (CSF) analysis showed albuminocytological dissociation with a high level of protein (2551 mg/L, normal: $<460 \mathrm{mg} / \mathrm{L}$ ) and no lymphocytes or tumor cells. CSF bacteriological cultures and PCR testing for herpes-family viruses were negative. CSF and blood protein electrophoresis revealed an intrathecal oligoclonal IgG pattern. Recent negative testing for HIV infection and viral hepatitis was not repeated. Table 1 summarizes the laboratory work-up.

After full neurological evaluation, the diagnosis of immune-mediated neuropathy was made and GBS was considered. The patient did not exhibit any severe symptoms such as respiratory alterations, autonomic involvement or bulbar palsy.

Further autoimmune laboratory work-up showed normal antinuclear and antineutrophil cytoplasmic 
A dabrafenib / trametinib pembrolizumab / epacadostat ipilimumab

Months before therapy
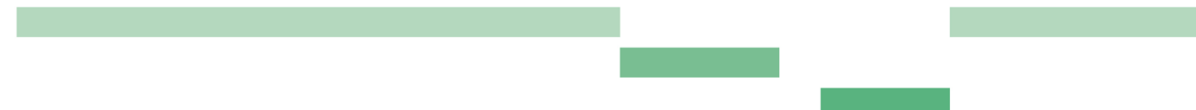

30

24

18

6

0

\section{B}
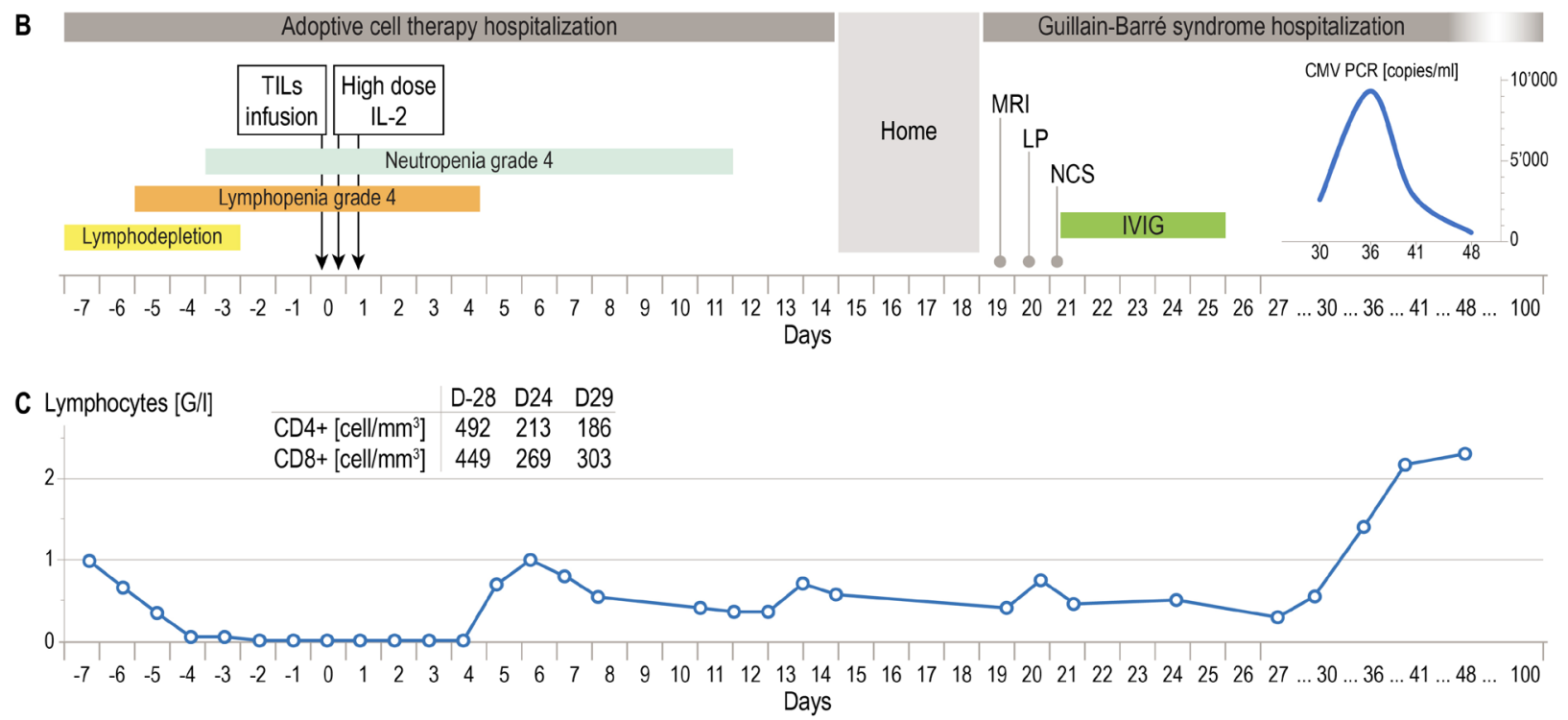

Figure 1 Timeline of events. (A) Previous oncological therapy. (B) Adoptive cell therapy and Guillain-Barré syndrome hospitalizations. (C) Total lymphocytes, CD4+ and CD8+ counts. CMV, cytomegalovirus; IL-2, interleukin-2; IVIG, intravenous immunoglobulin; LP, lumbar puncture; NCS, nerve conduction study; TIL, tumor-infiltrating lymphocyte.

antibodies, rheumatoid factor and blood complement values. Titers of myelin-associated or antiganglioside antibodies, as well as recent antibodies described in peripheral neuropathies directed against the node of Ranvier and the antifibroblast growth factor receptor 3 antibody, were negative. It is notable that negative results were not unexpected, as the prevalence of these antibodies is low
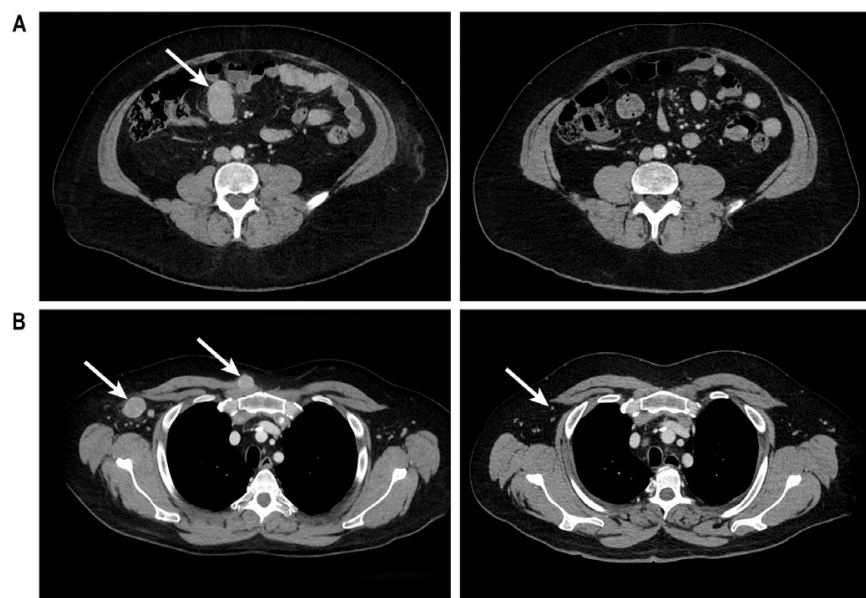

Baseline

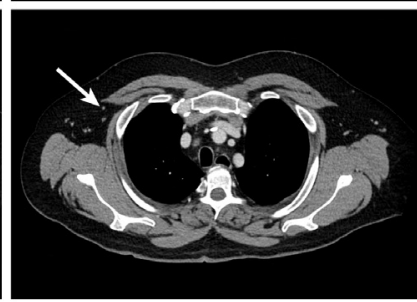

21 months post TIL-ACT

Figure 2 (A) Peritoneal implant. Left: at baseline (arrow), measuring $53 \times 32 \mathrm{~mm}$. Right: at month 21 , no longer seen. (B) Right axillary lymph node and right pectoral subcutaneous lesion. Left: at baseline, measuring 23 and $21 \mathrm{~mm}$ (arrows), respectively. Right, at month 21 , measuring 3 and $0 \mathrm{~mm}$ (arrow), respectively. ACT, adoptive cell therapy; TIL, tumorinfiltrating lymphocyte. in immune demyelinating neuropathies. An antineuronal antibody paraneoplastic panel was also negative. Table 1 summarizes the complete autoimmune laboratory work-up.

Importantly, a positive cytomegalovirus (CMV) viral load concomitant to the onset of GBS was detected in serum, with CMV PCR peak values of 9300 copies $/ \mathrm{mL}$ on day 36 post-TIL-ACT, consistent with CMV reactivation on lymphodepletion. Of note, the patient's serological profile at screening was consistent with prior exposure to CMV, but CMV PCR was negative on day 6 post-TIL-ACT, prior to developing neurological symptoms. No antiviral therapy was administered since the viral load decreased spontaneously on lymphoid reconstitution, with progressive return to undetectable levels within 1 month. Figure 1 shows the timeline of events.

A single 5-day course of intravenous immunoglobulin $(0.4 \mathrm{~g} / \mathrm{kg} /$ day) was administered 2 days after admission. The neurological manifestations of the patient progressively improved, with disappearance of symptoms of the upper limbs, and persistence of paresthesia and muscle weakness of the left lower limb. As he required intensive neurorehabilitation, he was transferred to a dedicated facility after 6 weeks of hospitalization. During the last follow-up at 21 months, the patient's neurological condition had completely recovered and he was able to walk normally. It is of importance to report that no other patient enrolled in this trial developed other unknown neurological side effect. 
The first tumor assessment obtained 4 weeks after cell transfer showed a partial radiological response with a target tumor mass reduction of $35 \%$. The response was durable, with further tumor shrinkage to up to $90 \%$ reduction 21 months after TIL infusion (figure 2).

Given that CMV-specific $\mathrm{T}$ cells have been isolated from TILs of patients with melanoma, ${ }^{5}$ we assessed the presence of such cells in the TIL product as well as in
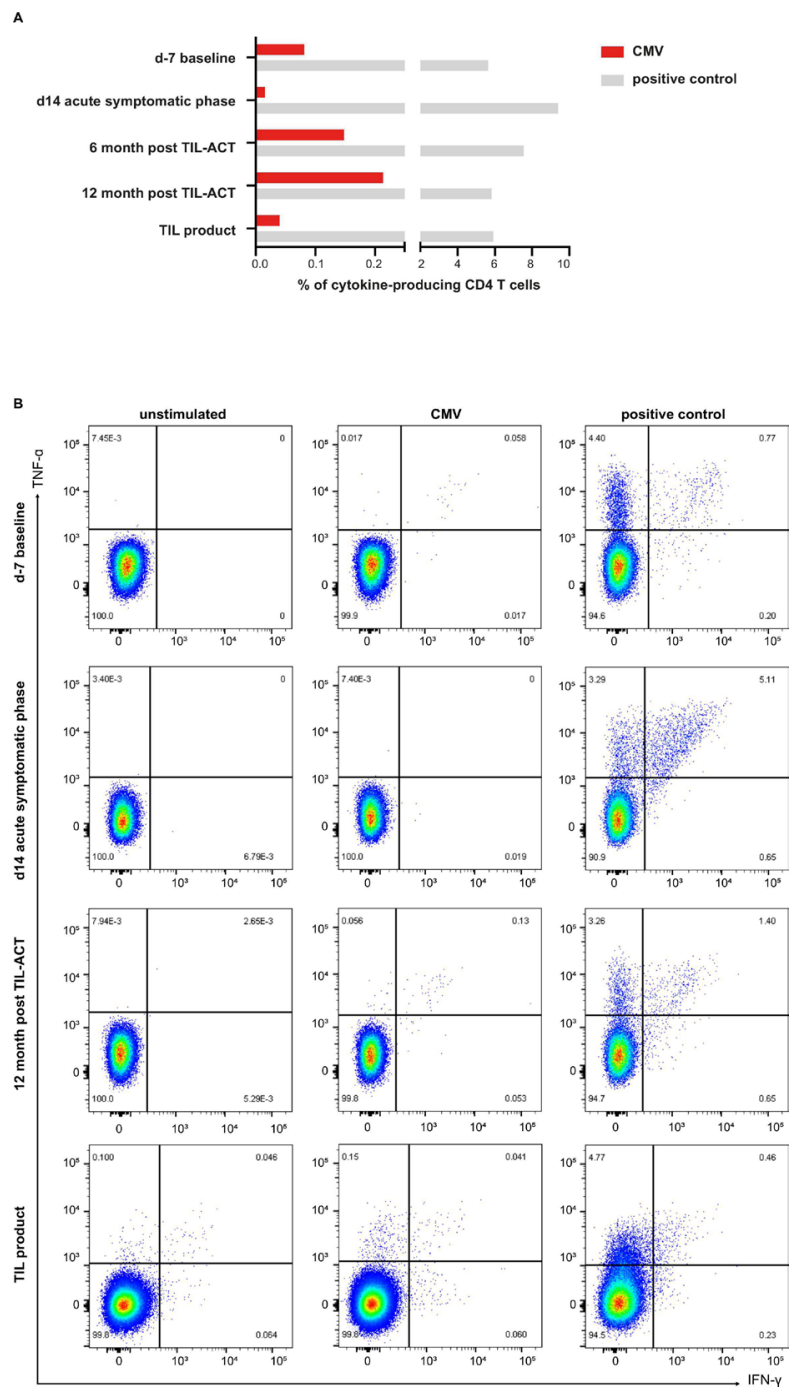

Figure 3 CD4+ responses to CMV lysate in peripheral blood mononuclear cells and TIL product at different time points. (A) Histogram: sum of interferon- $\gamma$ and tumor necrosis factor- $\alpha$ production on stimulation either with the CMV lysate or the positive control SEB after background subtraction provided by unstimulated CD4+ T cells. (B) FACS plots on viable CD4+ T cells. At baseline, there is a minor CMV CD4+ $\mathrm{T}$-cell response. This response disappears during the acute symptomatic phase, reflecting most probably the loss of CD4+ cells in the context of lymphodepletion caused by the chemotherapy. CMV CD4+ T-cell response reappears at 6 and 12 months post-TIL-ACT. By this time, lymphodepletion has recovered. Of note: cells were not anergic and responded well to the positive control (SEB). ACT, adoptive cell therapy; CMV, cytomegalovirus; FACS, Fluorescence-activated cell sorting; SEB, staphylococcal enterotoxin B; TIL, tumorinfiltrating lymphocyte. blood pre-TIL-ACT and post-TIL-ACT. We reasoned that if the patient experienced CMV reactivation post-T-cell infusion, the product would not contain any measurable frequencies of CMV-specific T cells to provide immediate protection during the lymphopenic period, while such cells would eventually reconstitute from endogenous precursors. We performed in vitro stimulation with CMV lysate of autologous PBMC obtained at the screening visit, during the acute symptomatic phase, at 6 and 12 months after the TIL-ACT, in addition to the TIL product. Flow cytometry analysis revealed a detectable frequency of circulating CD4+ T cells responding to CMV antigen with interferon- $\gamma$ and tumor necrosis factor- $\alpha$ at baseline and 6 and 12 months post-TIL-ACT, but not during the symptomatic phase. In addition, there were no detectable CMV-reactive T cells among the infused cells in the TIL product (figure 3A,B).

\section{DISCUSSION}

To our knowledge, GBS has never been described in patients who received TIL-ACT to date, nor has it been described in patients undergoing adoptive transfer of engineered $\mathrm{T}$ cells with chimeric antigen receptors. Recently, two cases of GBS were reported following ACT with autologous lymphocytes engineered with a NY-ESO-1 reactive T-cell receptor, and authors concluded this side effect was likely related to the adoptive therapy. ${ }^{6}$ Although in our clinical case it was not possible to identify the triggering agent with certainty, we documented a transient but clinically relevant CMV reactivation during lymphodepletion, which we considered to be the most plausible trigger.

GBS is an autoimmune neuropathy. Acute inflammatory demyelinating polyneuropathy (AIDP) and acute motor axonal neuropathy are the two main clinical manifestations of the disease, the most frequent being AIDP. Episodes are mostly triggered by an infectious process ${ }^{7}$ and show an acute and monophasic course, usually with rapidly progressive and bilateral ascending weakness. More severe cases may present with respiratory failure or autonomic involvement. ${ }^{8}$ The diagnosis is largely clinical but may be facilitated by additional investigations, such as CSF analysis and nerve conduction studies.

The exact immunopathological mechanism of GBS is multifactorial and complex, and not yet fully elucidated. ${ }^{79}$ A molecular mimicry against myelin antigens in peripheral nerves, triggered by precedent infections, is a widely accepted hypothesis. ${ }^{10}$ In this scenario, an immunological cascade leads to disruption of Schwann and/ or axonal membranes, resulting in signal conduction failure. The syndrome is mainly mediated by the humoral immune response, implying a wide range of antinerve autoantibodies inducing local complement activation and macrophage-mediated toxicity. ${ }^{7} \mathrm{~T}$ cells are also likely to play a supporting role, as they are a prerequisite for B-cell activation, maturation and antibody production. Nevertheless, the extent to which $\mathrm{T}$ cells might be involved in 
the immune response is still uncertain. Putative nerve antigens in GBS are yet to be characterized, although P0, P2, PMP22, gliomedin, contactin and moesin, among others, have been found to induce reactivity in $\mathrm{T}$ and $\mathrm{B}$ cells in some studies. ${ }^{711}$

Many infectious agents inducing the disease have been identified, the most common of which is Campylobacter jejuni in $25 \%-50 \%$ of adult patients with GBS. Of note, we did not search for $C$. jejuni infection as the patient presented no diarrhea. CMV infection has also been associated with GBS and is currently the second most frequent causative infectious agent in Western countries, accounting for $10 \%-20 \%$ of cases. ${ }^{12}$ Other frequent agents include Epstein-Barr virus, influenza A virus, hepatitis E virus, Mycoplasma pneumonia and Haemophilus influenza. ${ }^{13} 14$ The link between CMV and GBS was described for the first time more than 60 years ago and has become since then a frequent causative agent related to this syndrome. It is known that CMV infection may elicit molecular mimicry between the virus itself, such as CMV major capsid proteins, and myelin glycoproteins found in nerve tissues. ${ }^{15}$ CMV-induced GBS has been observed in patients presenting a primary CMV infection ${ }^{12}{ }^{16}$ as well as after CMV reactivation on immunosuppression, for example, in patients with solid-organ transplantation. ${ }^{17}$ Recently, a systematic review analyzing 17 cases of GBS in renal transplant patients identified CMV as the most common trigger for this condition. ${ }^{18}$ Generally, patients with CMV-triggered GBS were more likely to show predominantly sensory defects rather than axonal disease, as in our patient's case, revealing specificities of distribution of the target autoantigen related to CMV molecular mimicry. While our patient did not present with a primary CMV infection, he presented with a reactivation of CMV considered as a potential trigger for the neurological autoimmune reaction. This viral reactivation most probably occurred in the context of chemotherapy-induced immunosuppression.

Lymphodepletion is a crucial component of the ACT-TIL therapy as it increases the effectiveness of the treatment. ${ }^{19}$ In addition to depleting endogenous lymphocytes, which act as sinks for cytokines and are capable of decreasing T-cell activity, other immunosuppressive cells, such as myeloid-derived suppressor cells and regulatory $\mathrm{T}$ cells, are also depleted, therefore favoring engraftment and long-lasting persistence of the transferred $\mathrm{T}$ cells. It is possible that the favorable immune milieu created by the lymphodepletion and lymphoid reconstitution in the context of low regulatory $\mathrm{T}$ cells could also facilitate the breaking of tolerance to self-antigens or lower the threshold for cross-reactivity in the case of molecular mimicry. A combination of high-dose cyclophosphamide $\left(60 \mathrm{mg} / \mathrm{kg}\right.$ for 2 days) and fludarabine $\left(25 \mathrm{mg} / \mathrm{m}^{2}\right.$ for 5 days) is used in most TIL-ACT protocols for lymphodepletion. ${ }^{1}$ While fludarabine is known to have a potential dose-dependent neurological toxicity, this typically affects the central nervous system and is observed mainly at much higher doses than used in the current setting (around $100 \mathrm{mg} / \mathrm{m}^{2}$ for 5 days).$^{20}$ Furthermore, although chemotherapy itself can in principle be neurotoxic, it mainly causes direct axonal damage rather than demyelination as observed in the present case. We therefore do not consider chemotherapy as the etiology of GBS in our patient, but rather as a causative agent for immunosuppression enabling CMV reactivation.

Besides chemotherapy, high-dose IL-2 is another putative candidate to be discussed in the context of neurological side effects. IL-2 is administered after adoptive transfer to promote proliferation, expansion and successful engraftment of infused TILs ${ }^{21}$ and to enhance the cytolytic activity and effector functions of TILs in the tumor. In our protocol, IL-2 is administered in high-dose boluses of $720,000 \mathrm{UI} / \mathrm{kg}$ for a maximum of 8 doses. The most common neurological adverse events of IL-2 described in ACT-TIL trials include mental status changes, including confusion, disorientation and somnolence, as well as dizziness. ${ }^{22}$ Altered sleeping patterns have also been described, as well as agitation and paranoia. GBS has been previously reported in at least one patient with melanoma treated with high-dose IL-2 monotherapy; this patient had not been previously treated with checkpoint inhibitors. ${ }^{23}$ Although the pathophysiological mechanism is not well elucidated, a potential relationship with IL-2 cannot be formally excluded.

The TIL product itself could be considered a potential causative agent for GBS as well. In our protocol, the melanoma TIL final product is composed of autologous $\mathrm{T}$ cells isolated from the patient's own tumor tissue and expanded ex vivo in the presence of recombinant human IL-2, a soluble anti-CD3 antibody and autologous feeder cells. We use young 'bulk' TILs composed of both CD4+ and CD8+ T-cell subsets, without selection based on tumor reactivity. Our patient received a T-cell profile with equal proportions of CD4+ and CD8+ cells. Although T cells can be found in GBS lesions, ${ }^{24}$ their involvement remains unclear and the leading pathophysiological mechanism involves rather B-cell immunity with secondary antibodymediated cytotoxicity. This is consistent with the lack of CMV-specific T cells in the product or on day 6 when $T$ cells had already reconstituted in the host.

Interestingly, cases of GBS have been reported in patients treated with both CTLA-4 and PD-1 immune checkpoint inhibitors, all of which occurred during treatment. ${ }^{25}$ Our patient had previously received an anti-PD1 antibody in combination with an inhibitor of indoleamine 2,3-dioxygenase-1 in the setting of a clinical trial, with the last dose 13 months before TIL-ACT, as well as therapy with anti-CTLA- 4 antibody, with the last dose 8 months before TIL-ACT. It is thus unlikely that the side effect would be directly related to these prior lines of therapy.

\section{CONCLUSION}

In conclusion, we describe for the first time a case of GBS occurring in the acute phase after TIL-ACT. The report of rare cases such as the one presented here is of 
utter importance to build on the knowledge of immune cellular therapies. The full-spectrum of adverse events that may occur in this particular period of lymphodepletion (with consequent vulnerability to opportunistic infections and viral reactivation) and IL-2 stimulation, where the tight regulation of immune suppression and immune activation is powerfully perturbed, is not yet fully understood. This case highlights the relevance of specialized management of these therapies, with multidisciplinary approaches ensuring accurate diagnosis and effective treatment in order to minimize the impact on the potential benefit of the cellular therapy.

\section{Twitter Benita Wolf @imwolfb1}

Acknowledgements The authors thank the patient and his family for entrusting them with his care.

Contributors A0: main treating physician, analyzed and interpreted the patient's case, wrote and edited the manuscript. AHo, BW, BNR, MOdO, DC: treated the patient and reviewed the manuscript. AA: performed translational research. TK: performed nerve conduction studies, treated the patient and reviewed the manuscript. VZ: trial coordinator and reviewed the manuscript. PG: worked in cell production and reviewed the manuscript. LK: reviewed the manuscript. OM: reviewed the manuscript. SZ and LT: treated the patient, interpreted the case and reviewed the manuscript. AHa: performed translational research. GC: supervised the clinical management, interpreted the case and reviewed the manuscript.

Funding The study was supported by institutional funding from the Ludwig Institute for Cancer Research and the Canton de Vaud, as well as BMS.

Competing interests $\mathrm{GC}$ has received grants or research support from or is coinvestigator in clinical trials by BMS, Celgene, Boehringer Ingelheim, Roche, lovance and Kite, and has received honoraria for consultations or presentations by Roche, Genentech, BMS, AstraZeneca, Sanofi-Aventis, Nextcure and GeneosTx. SZ reports travel grants by AstraZeneca in the last 12 months.

\section{Patient consent for publication Obtained.}

Provenance and peer review Not commissioned; externally peer reviewed.

Open access This is an open access article distributed in accordance with the Creative Commons Attribution Non Commercial (CC BY-NC 4.0) license, which permits others to distribute, remix, adapt, build upon this work non-commercially, and license their derivative works on different terms, provided the original work is properly cited, appropriate credit is given, any changes made indicated, and the use is non-commercial. See http://creativecommons.org/licenses/by-nc/4.0/.

\section{ORCID iD}

Denis Comte http://orcid.org/0000-0002-6605-1498

\section{REFERENCES}

1 Rosenberg SA, Yang JC, Sherry RM, et al. Durable complete responses in heavily pretreated patients with metastatic melanoma using T-cell transfer immunotherapy. Clin Cancer Res 2011;17:4550-7.

2 Dafni U, Michielin O, Lluesma SM, et al. Efficacy of adoptive therapy with tumor-infiltrating lymphocytes and recombinant interleukin-2 in advanced cutaneous melanoma: a systematic review and metaanalysis. Ann Oncol 2019;30:1902-13.
3 Wolf B, Zimmermann S, Arber C, et al. Safety and tolerability of adoptive cell therapy in cancer. Drug Saf 2019;42:315-34.

4 Weber JS, Yang JC, Atkins MB, et al. Toxicities of immunotherapy for the practitioner. J Clin Oncol 2015;33:2092-9.

5 Lérias JR, Paraschoudi G, Silva I, et al. Clinically relevant immune responses against cytomegalovirus: implications for precision medicine. Int J Mol Sci 2019;20. doi:10.3390/ijms20081986. [Epub ahead of print: 23 Apr 2019].

6 Joseph J, Nathenson MJ, Trinh VA, et al. Guillain-Barre syndrome observed with adoptive transfer of lymphocytes genetically engineered with an NY-ESO-1 reactive T-cell receptor. J Immunother Cancer 2019;7:296.

7 Willison HJ, Jacobs BC, van Doorn PA. Guillain-Barré syndrome. Lancet 2016;388:717-27.

8 Fokke C, van den Berg B, Drenthen J, et al. Diagnosis of Guillain-Barré syndrome and validation of Brighton criteria. Brain 2014:137:33-43.

9 Feasby TE, Hahn AF, Brown WF, et al. Severe axonal degeneration in acute Guillain-Barré syndrome: evidence of two different mechanisms? J Neurol Sci 1993;116:185-92.

10 Willison HJ, Goodyear CS. Glycolipid antigens and autoantibodies in autoimmune neuropathies. Trends Immunol 2013;34:453-9.

11 Makowska A, Pritchard J, Sanvito L, et al. Immune responses to myelin proteins in Guillain-Barré syndrome. J Neurol Neurosurg Psychiatry 2008;79:664-71.

12 Orlikowski D, Porcher R, Sivadon-Tardy V, et al. Guillain-Barré syndrome following primary cytomegalovirus infection: a prospective cohort study. Clin Infect Dis 2011;52:837-44.

13 Jacobs BC, Rothbarth PH, van der Meché FG, et al. The spectrum of antecedent infections in Guillain-Barré syndrome: a case-control study. Neurology 1998;51:1110-5.

14 Geurtsvankessel CH, Islam Z, Mohammad QD, et al. Hepatitis E and Guillain-Barre syndrome. Clin Infect Dis 2013;57:1369-70.

15 Brok HPM, Boven L, van Meurs M, et al. The human CMV-UL86 peptide 981-1003 shares a crossreactive T-cell epitope with the encephalitogenic MOG peptide 34-56, but lacks the capacity to induce EAE in rhesus monkeys. J Neuroimmunol 2007;182:135-52.

16 Visser LH, van der Meché FG, Meulstee J, et al. Cytomegalovirus infection and Guillain-Barré syndrome: the clinical, electrophysiologic, and prognostic features. Dutch Guillain-Barré Study Group. Neurology 1996;47:668-73.

17 El-Sabrout RA, Radovancevic B, Ankoma-Sey V, et al. GuillainBarré syndrome after solid organ transplantation. Transplantation 2001;71:1311-6.

18 Ostman C, Chacko B. Guillain-Barré syndrome post renal transplant: a systematic review. Transpl Infect Dis 2019;21:e13021.

19 Klebanoff CA, Khong HT, Antony PA, et al. Sinks, suppressors and antigen presenters: how lymphodepletion enhances T cell-mediated tumor immunotherapy. Trends Immunol 2005;26:111-7.

20 Warrell RP, Berman E. Phase I and II study of fludarabine phosphate in leukemia: therapeutic efficacy with delayed central nervous system toxicity. J Clin Oncol 1986;4:74-9.

21 Atkins MB, Lotze MT, Dutcher JP, et al. High-Dose recombinant interleukin 2 therapy for patients with metastatic melanoma: analysis of 270 patients treated between 1985 and 1993. J Clin Oncol 1999;17:2105-16.

22 Schwartzentruber DJ. Guidelines for the safe administration of highdose interleukin-2. J Immunother 2001;24:287-93.

23 Buchbinder El, Gunturi A, Perritt J, et al. A retrospective analysis of high-dose interleukin-2 (HD IL-2) following ipilimumab in metastatic melanoma. J Immunother Cancer 2016;4:52.

24 Wanschitz J, Maier H, Lassmann $\mathrm{H}$, et al. Distinct time pattern of complement activation and cytotoxic T cell response in GuillainBarré syndrome. Brain 2003;126:2034-42.

25 Supakornnumporn S, Katirji B. Guillain-Barré syndrome triggered by immune checkpoint inhibitors: a case report and literature review. $J$ Clin Neuromuscul Dis 2017;19:80-3. 